\title{
The effects of a rise in cigarette price on cigarette consumption, tobacco taxation revenues, and of smoking-related deaths in 28 EU countries- applying threshold regression modelling
}

\author{
Chun-Yuan Yeh ${ }^{1}$, Christian Schafferer', Jie-Min Lee ${ }^{2 *}$, Li-Ming Ho ${ }^{3}$ and Chi-Jung Hsieh ${ }^{4}$
}

\begin{abstract}
Background: European Union public healthcare expenditure on treating smoking and attributable diseases is estimated at over $€ 25 \mathrm{bn}$ annually. The reduction of tobacco consumption has thus become one of the major social policies of the EU. This study investigates the effects of price hikes on cigarette consumption, tobacco tax revenues and smoking-caused deaths in 28 EU countries.

Methods: Employing panel data for the years 2005 to 2014 from Euromonitor International, the World Bank and the World Health Organization, we used income as a threshold variable and applied threshold regression modelling to estimate the elasticity of cigarette prices and to simulate the effect of price fluctuations.

Results: The results showed that there was an income threshold effect on cigarette prices in the $28 \mathrm{EU}$ countries that had a gross national income (GNI) per capita lower than US\$5418, with a maximum cigarette price elasticity of -1.227 . The results of the simulated analysis showed that a rise of $10 \%$ in cigarette price would significantly reduce cigarette consumption as well the total death toll caused by smoking in all the observed countries, but would be most effective in Bulgaria and Romania, followed by Latvia and Poland. Additionally, an increase in the number of MPOWER tobacco control policies at the highest level of achievment would help reduce cigarette consumption.

Conclusions: It is recommended that all EU countries levy higher tobacco taxes to increase cigarette prices, and thus in effect reduce cigarette consumption. The subsequent increase in tobacco tax revenues would be instrumental in covering expenditures related to tobacco prevention and control programs.
\end{abstract}

Keywords: Cigarette price, Cigarette consumption, Threshold regression model-Smoking-attributable mortality, European Union

\section{Background}

\section{Smoking prevalence and tobacco control}

In 2017, every fourth EU citizen smoked, and the annual death toll from smoking was approximately 700,000 [1]. EU public healthcare expenditure on treating smoking and attributable diseases is estimated at over $€ 25 \mathrm{bn}$ annually, constituting a considerable burden on public

\footnotetext{
* Correspondence: jmlee866@yahoo.com.tw

${ }^{2}$ Department of Shipping and Transportation Management, National

Kaohsiung Marine University, 142, Hai-Chuan Rd. Nan-Tzu, Kaohsiung, Taiwan Full list of author information is available at the end of the article
}

health care systems. Moreover, $€ 8 \mathrm{bn}$ is reportedly lost annually in productivity from deaths, absenteeism and early retirement linked to smoking [2].

The reduction of tobacco consumption has thus become one of the major social policies of the EU and the necessity of implementing the six MPOWER tobacco control policies proposed by the World Health Organisation (WHO) in 2008: (i) increases in the tobacco tax; (ii) monitoring of tobacco usage; (iii) support for quitters; (iv) creation of a smoking-free environment; (v) warning against the dangers of tobacco; (vi) and banning 
tobacco advertising, promotion and sponsorship. According to Levy et al., if 41 countries across the world had implemented at least one MPOWER policy between 2007 and 2010, the number of smokers would have been cut by 14.8 million, and 7.4 million would have avoided death caused by smoking [3]. In particular, increased tobacco taxation would have saved 3.5 million people, suggesting that taxation would have been the most effective single intervention to reduce demands for cigarettes by raising cigarette prices [3]. The relationship between tobacco price and consumption is also illustrated by the fact that EU countries with lower cigarette prices tend to have higher rates of smoking [4]. Moreover, unlike other policy tools, such as bans on tobacco advertising, taxation not only effectively decreases tobacco consumption but also has the beneficial side effect of increasing national tax revenues $[5,6]$.

\section{Price elasticities and cigarette demand}

The effectiveness of tax increases on cigarette consumption is mainly determined by cigarette price elasticity. Although numerous studies have demonstrated that cigarette price elasticities of low- and middle-income are higher than in high-income countries [7], other studies have shown that price elasticity in several developing countries were similar to those of developed countries $[8,9]$. Differences in cigarette price elasticities may have been caused by applying different demand functions, information patterns, and estimation methods [10]. Therefore, employing the same demand function, information pattern, and estimation method can facilitate a standardized comparison of the price elasticity of demand for cigarettes among different countries.

Studies have also shown that there are geographical variations in smoking behaviour [11, 12]. In Eastern European countries, such as Slovenia, Romania and Slovakia, tobacco prevalence in rural and remote areas is higher than in urban areas (World Bank. World Development Indicators (WDI)), whereas in Western European countries, such as Germany, Sweden, Finland and Denmark, the opposite has been reported [13]. Smokers living in rural and remote areas tend to have a lower social and economic status and are more sensitive to price fluctuations $[14,15]$; hence, this group reportedly is more likely to opt for lower-priced products, or consider cessation [16, 17]. Moreover, cigarette prices in Eastern European countries are considerably lower than in other parts of Europe, leading to increased illicit trading in cigarettes and to subsequent changes in consumption patterns throughout the European Union [18].

Numerous previous studies have adopted a linear model to estimate cigarette demand structure $[4,9,19]$. However, this estimation method might fail to fully show the pricevolume relationship. Huang and Yang estimated the cigarette demand relationship in all states across the US and found that there were income threshold effects in the demand for cigarettes [20], which indicates that there are differences in the cigarette price elasticity of demand at different income thresholds.

\section{The goals of this study}

This study employed threshold regression modelling and used income as a threshold variable to estimate the price elasticity of cigarette demand. Furthermore, a cigarette price increase of $10 \%$ was used to analyse the effects of price increases on cigarette consumption, tobacco taxation, and the death toll of smoking. The findings of this study may serve as an important reference for EU health management authorities to revise tobacco prevention and control policies.

\section{Methods}

\section{Study design and data}

In this study, data of all $28 \mathrm{EU}$ countries were collected to construct a cigarette demand structure model. One dependent variable and five independent variables were considered. Per capita cigarette consumption for those aged 15 and over was chosen as the dependent variable. Independent variables comprised cigarette prices, cigarette prices in Eastern European countries, gross national income (GNI), rural population, and the number of MPOWER measures implemented at the highest level of achievement.

Data regarding cigarette consumption, cigarette prices, and cigarette prices in Eastern European countries were extracted from the 2005-2014 Euromonitor International market research database [21]. Euromonitor International is recognized as a leading independent provider of global business intelligence, specialized in creating worldwide data and analysis on consumer products and services. Consumption of cigarette products was calculated based on annual cigarette consumption per capita for those aged 15 and over. The retail price for a pack of cigarettes in each country was calculated by dividing cigarette sales revenues by cigarette consumption, which was further deflated using consumer price indexes.

Cigarette price in Eastern European countries refers to the combined average cigarette price in Estonia, Latvia, Lithuania, Poland, Czech Republic, Slovakia, Hungary, Romania, Slovenia, Croatia and Bulgaria.

GNI per capita data were converted to US dollars using the World Bank Atlas method [22], divided by the midyear population, and deflated based on consumer price indexes. Required data were retrieved from the World Bank's database. In this study, the ratio of the rural population to the total population was used in the analysis. Rural population refers to the number of people living in rural areas as defined by the National Statistical 
Offices and was calculated as the difference between the total population and the urban population. Data on the ratio of the rural population to the total population are World Bank estimates [22] and based on the United Nations, World Urbanization Prospects [23].

As to the number of MPOWER measures implemented at the highest level of achievement by each country in each year, figures for the years 2007 to 2014 were taken from the 2015 WHO report on global tobacco epidemic [17]. Data for the years 2005, 2006 and 2015 were unavailable and treated as missing data in the analysis.

\section{Data characteristics}

Table 1 shows the list of variables used in the analysis and the data characteristics. In 2014, per capita cigarette consumption in the $28 \mathrm{EU}$ countries for adults aged 15 years and over was the highest in Slovenia at 2098 cigarettes, followed by the Czech Republic (1720 cigarettes), Austria (1631 cigarettes), Greece (1552 cigarettes), and Romania (1501 cigarettes); those of the other EU countries were all less than 1500 cigarettes. In 2014, the average real retail price was the highest in United Kingdom at US\$9.48 per pack, followed by Ireland (US\$9.04). In addition, the average highest number of MPOWER measures implemented in Ireland, Spain, and the United Kingdom was 3, followed by Belgium, Bulgaria, Denmark, Greece, Malta, and the Netherlands at 2; whereas in the remaining EU countries the number of measures were below 2 .

\section{Empirical specification and analysis}

To calculate cigarette price elasticity, a cigarette demand structure model was constructed using cigarette consumption as the dependent variable and cigarette price, cigarette prices in Eastern Europe countries, GNI, rural population, and the highest number of MPOWER measures implemented as explanatory variables. Cigarette price elasticity was estimated with income as the threshold variable using the threshold regression model of panel data from Hansen [24].

The baseline cigarette demand structure model of the $28 \mathrm{EU}$ countries is as follows:

$$
\begin{aligned}
\ln C_{i t} & =\beta_{1 i}+\beta_{2} \ln P_{i t}+\beta_{3} \ln G N I_{i t}+\beta_{4} \text { Rural }_{i t} \\
& +\beta_{5} M P_{i t}+\beta_{6} \ln N e i P_{i t}+\varepsilon_{i t}
\end{aligned}
$$

Where,

$C_{i t}$ : the annual cigarette consumption per capita in the population aged 15 years and over in country $i$ in year $t$.

$P_{i t}$ : the cigarette price per cigarette in country i in year $\mathrm{t}$. $G N I_{i t}$ : the per capita national income in country i in year $\mathrm{t}$.
Rural $_{i t}$ : the rural population percentage in country i in year $\mathrm{t}$.

$M P_{i t}$ : the highest number of MPOWER measures implemented in country $\mathrm{i}$ in year $\mathrm{t}$.

$N e i P_{i t}$ : cigarette prices per cigarette in Eastern European country $i$ in year $t$.

Formula (1) is the traditional constant-elasticity loglinear demand model, but the influence of cigarette prices on cigarette consumption may not be limited to a single pattern. That is, there may also be non-linear structural relationships, such as income threshold effects on the demand for tobacco products [20]. We thus used income as the threshold variable in the threshold regression model to estimate the elasticity of cigarette prices and to simulate the effects of price fluctuations. One feature of a threshold regression model is that threshold variables are ordered so as to be a structure breakpoint of regime variation. The estimated reference points are divided into different regimes by variable value, which is greater or smaller than the threshold value.

The panel threshold regression model is often "demeaned" first, in order to eliminate the individual effect $\beta_{i}$ [24]. If our baseline model contains three regimes of national incomes that are conditional on two threshold values, Eq. 1 can be derived as

$$
\begin{aligned}
\ln C_{i t}^{*}=\beta_{21} \ln P_{i t}^{*}\left(G N I \leq \gamma_{1}\right)+\beta_{22} \ln P_{i t}^{*}\left(\gamma_{1} \leq G N I \leq \gamma_{2}\right) & \\
& +\beta_{23} \ln P_{i t}^{*}\left(G N I>\gamma_{2}\right)+ \\
\beta 31 \ln G N I_{i t}^{*}\left(G N I \leq \gamma_{1}\right)+\beta_{32} \ln G N I_{i t}^{*}\left(\gamma_{1} \leq G N I \leq \gamma_{2}\right) & +\beta_{33} \ln G N I_{i t}^{*}\left(G N I>\gamma_{2}\right) \\
+ & \beta_{4} \text { Rural }_{i t}^{*}+\beta_{5} M P_{i t}^{*}+\beta_{6} \ln N e i P_{i t}^{*}+\varepsilon_{i t}^{*}
\end{aligned}
$$

Where $\bar{C}_{i}=T^{-1} \sum_{t=1}^{T} C_{i t} ; C_{i t}^{*}=C_{i t}-\overline{C_{i}} ; P_{i t}^{*}=P_{i t}-\overline{P_{i}}$; $G N I_{i t}^{*}=G_{i t}-\overline{G N I}_{i} ; \quad$ Rural $_{i t}^{*}=$ Rural $_{i t}-\overline{\text { Rural }}_{i} ; \quad$ MP $_{i t}^{*}$ $=M P_{i t}-\overline{M P}_{i} ; N e i P_{i t}^{*}=N e i P_{i t}-\overline{N e i P}_{i} ; \varepsilon_{i t}^{*}=\varepsilon_{i t}-\bar{\varepsilon}_{i} ;$ and $\gamma_{1}$ and $\gamma_{2}$ are the two threshold values that control GNI $I_{i t}$. We use ordinary least squares (OLS) to estimate Eq. 2. The selection of threshold variables in the empirical model can be determined by economic theory or statistical testing. In the process of statistical testing, the null hypothesis $\left(\mathrm{H}_{0}: \beta_{i}\right.$ are all the same) maintains that a traditional log-linear model is sufficient. In this article, we applied the likelihood ratio to test the nonlinear relationship. In such cases, further testing is required to determine single, double or triple thresholds. In order to avoid heteroskedasticity, the inconsistency of standard errors caused by serial correlations and heterogeneity of the residual terms, consistent correction was performed according to White (1980) [25]. Statistical software packages Gauss and Stata were used to perform the analysis. 
Table 1 Comparison of cigarette consumption, retail prices and gross national income from 2005 to 2014 in the European Union

\begin{tabular}{|c|c|c|c|c|c|c|c|c|c|c|c|}
\hline \multirow[t]{2}{*}{ Countries } & \multicolumn{3}{|c|}{$\begin{array}{l}\text { Per capita legal cigarette } \\
\text { consumption of population } \\
\text { aged over } 15 \text { (No. cigs) }\end{array}$} & \multicolumn{3}{|c|}{$\begin{array}{l}\text { Real retail price } \\
\text { of a pack of legal } \\
\text { cigarettes (US\$) }\end{array}$} & \multicolumn{3}{|c|}{$\begin{array}{l}\text { Real GNI per } \\
\text { capita (US\$) } \\
\text { Consumer price } \\
\text { index }(2005=100)\end{array}$} & \multirow[t]{2}{*}{$\begin{array}{l}\text { The number of } \\
\text { MPOWER measures } \\
\text { at the highest level of } \\
\text { achievement in } 2014\end{array}$} & \multirow[t]{2}{*}{$\begin{array}{l}\text { Share of total } \\
\text { taxes in the retai } \\
\text { price in } 2014\end{array}$} \\
\hline & 2005 & 2014 & $\begin{array}{l}\text { Change } \\
(2005 \sim 2014)\end{array}$ & 2005 & 2014 & $\begin{array}{l}\text { Change } \\
(2005 \sim 2014)\end{array}$ & 2005 & 2014 & $\begin{array}{l}\text { Change } \\
(2005 \sim 2014)\end{array}$ & & \\
\hline Austria & 1688 & 1631 & $-3.38 \%$ & 3.27 & 4.59 & $40.37 \%$ & 38,500 & 41,765 & $8.48 \%$ & 1 & $74.00 \%$ \\
\hline Belgium & 1156 & 966 & $-16.44 \%$ & 4.5 & 5.24 & $16.44 \%$ & 37,850 & 39,561 & $4.52 \%$ & 2 & $75.92 \%$ \\
\hline Bulgaria & 2750 & 1282 & $-53.38 \%$ & 0.8 & 1.6 & $100.00 \%$ & 3760 & 5261 & $39.92 \%$ & 2 & $82.65 \%$ \\
\hline Croatia & 1735 & 1330 & $-23.34 \%$ & 1.69 & 2.74 & $62.13 \%$ & 9870 & 10,471 & $6.09 \%$ & 0 & $75.26 \%$ \\
\hline $\begin{array}{l}\text { Czech } \\
\text { Republic }\end{array}$ & 2183 & 1720 & $-21.21 \%$ & 1.77 & 2.79 & $57.63 \%$ & 12,380 & 15,246 & $23.15 \%$ & 1 & $77.42 \%$ \\
\hline Cyprus & 1371 & 1400 & $2.12 \%$ & 2.06 & 2.72 & $32.04 \%$ & 21,490 & 22,597 & $5.15 \%$ & 0 & $77.47 \%$ \\
\hline Denmark & 1472 & 1080 & $-26.63 \%$ & 4.06 & 5.15 & $26.85 \%$ & 49,620 & 52,632 & $6.07 \%$ & 2 & $74.75 \%$ \\
\hline Estonia & 1481 & 1480 & $-0.07 \%$ & 1.25 & 2.27 & $81.60 \%$ & 9710 & 13,436 & $38.37 \%$ & 1 & $77.24 \%$ \\
\hline Finland & 954 & 789 & $-17.30 \%$ & 4.05 & 5.44 & $34.32 \%$ & 40,100 & 40,954 & $2.13 \%$ & 1 & $81.53 \%$ \\
\hline France & 898 & 682 & $-24.05 \%$ & 5 & 7.07 & $41.40 \%$ & 36,000 & 37,487 & $4.13 \%$ & 1 & $80.3 \%$ \\
\hline Germany & 1175 & 980 & $-16.60 \%$ & 4.49 & 5.23 & $16.48 \%$ & 35,880 & 41,335 & $15.20 \%$ & 1 & $72.9 \%$ \\
\hline Greece & 3016 & 1552 & $-48.54 \%$ & 2.46 & 3.3 & $34.15 \%$ & 22,510 & 18,212 & $-19.09 \%$ & 2 & $79.95 \%$ \\
\hline Hungary & 1366 & 936 & $-31.48 \%$ & 1.52 & 1.88 & $23.68 \%$ & 10,430 & 9202 & $-11.77 \%$ & 1 & $77.26 \%$ \\
\hline Ireland & 1364 & 685 & $-49.78 \%$ & 6.01 & 9.04 & $50.42 \%$ & 44,500 & 32,362 & $-27.28 \%$ & 3 & $77.8 \%$ \\
\hline Italy & 1569 & 1147 & $-26.90 \%$ & 3.57 & 4.9 & $37.25 \%$ & 32,390 & 29,248 & $-9.70 \%$ & 1 & $75.68 \%$ \\
\hline Latvia & 2089 & 892 & $-57.30 \%$ & 0.81 & 2.02 & $149.38 \%$ & 7360 & 10,293 & $39.85 \%$ & 1 & $76.89 \%$ \\
\hline Lithuania & 1079 & 965 & $-10.57 \%$ & 1.26 & 2.42 & $92.06 \%$ & 7550 & 11,421 & $51.27 \%$ & 1 & $75.76 \%$ \\
\hline Luxembourg & 1110 & 854 & $-23.06 \%$ & 4.57 & 4.63 & $1.31 \%$ & 70,340 & 62,685 & $-10.88 \%$ & 1 & $70.24 \%$ \\
\hline Malta & 1661 & 1048 & $-36.91 \%$ & 2.76 & 3.77 & $36.59 \%$ & 14,380 & 19,645 & $36.61 \%$ & 2 & $74.63 \%$ \\
\hline Netherlands & 837 & 659 & $-21.27 \%$ & 3.13 & 5.92 & $89.14 \%$ & 42,390 & 43,804 & $3.34 \%$ & 2 & $73.4 \%$ \\
\hline Poland & 1926 & 1136 & $-41.02 \%$ & 1.17 & 2.52 & $115.38 \%$ & 7330 & 10,858 & $48.13 \%$ & 1 & $80.29 \%$ \\
\hline Portugal & 1754 & 852 & $-51.43 \%$ & 2.29 & 4.62 & $101.75 \%$ & 18,550 & 18,342 & $-1.12 \%$ & 1 & $74.51 \%$ \\
\hline Romania & 1604 & 1501 & $-6.42 \%$ & 0.23 & 0.55 & $139.13 \%$ & 3930 & 6190 & $57.51 \%$ & 1 & $75.41 \%$ \\
\hline Slovakia & 1136 & 1381 & $21.57 \%$ & 1.26 & 1.83 & $45.24 \%$ & 11,280 & 14,410 & $27.75 \%$ & 1 & $81.54 \%$ \\
\hline Slovenia & 2281 & 2098 & $-8.02 \%$ & 1.54 & 2.47 & $60.39 \%$ & 18,440 & 19,217 & $4.21 \%$ & 1 & $80.41 \%$ \\
\hline Spain & 2212 & 911 & $-58.82 \%$ & 2.79 & 4.09 & $46.59 \%$ & 25,930 & 24,424 & $-5.81 \%$ & 3 & $78.09 \%$ \\
\hline Sweden & 2212 & 666 & $-69.89 \%$ & 4.93 & 6.37 & $29.21 \%$ & 45,350 & 54,339 & $19.82 \%$ & 1 & $68.84 \%$ \\
\hline $\begin{array}{l}\text { United } \\
\text { Kingdom }\end{array}$ & 843 & 568 & $-32.62 \%$ & 7.87 & 9.48 & $20.46 \%$ & 41,150 & 34,194 & $-16.90 \%$ & 3 & $82.16 \%$ \\
\hline
\end{tabular}

To determine the effects of cigarette price hikes on cigarette consumption, cigarette consumption in 2015 was set as the baseline for this study. We introduced $10 \%$ increments in cigarette prices to simulate changes in future cigarette consumption based on the cigarette price elasticity estimated in this study. Changes in tobacco tax revenues were calculated based on changes in consumption due to price increases.

The number of averted smoking-attributable deaths (SADs) derived from the simulated impact of price increments on the reduction in smokers and was adjusted for the fact that smoking cessation still carries considerable risks of early death [26]. The applied mortality adjustment factors were calculated for each country surveyed, assuming that $95,75,70,50$ and $10 \%$ of those who ceased smoking when aged 15 to 29,30 to 39,40 to 49,50 to 59 and at least 60 years, respectively, would remain unaffected by their previous smoking habits [27]. Data on population stratification were extracted from the Eurostat database. 


\section{Results}

\section{Regression results}

Table 2 shows the test results of the threshold effect. For the observed EU countries, the test for one threshold had a value of 43.66, suggesting that price elasticities may indeed fluctuate as a result of changing income levels. The panel threshold model seems thus to be more appropriate to apply in this study than the traditional panel data model. Next, the value of the LR with two thresholds was 36.61, which allowed us to reject the null hypothesis that there was no presence of a threshold effect at the $10 \%$ significance level. Furthermore, there were two significant income threshold values in cigarette prices in the EU at US\$5418 and at US\$8385. As the sum of squared errors (SSE) of the double-threshold model $(0.311)$ is lower than that of the single-threshold model (0.355), the double-threshold model seems to be more appropriate.

This study thus used three income regimes with different GNI per capita in the analysis. As illustrated in
Table 3, Bulgaria and Romania were assigned to the first, Latvia and Poland to the second, and the remaining 24 EU countries to the third income regime.

\section{Elasticity estimates}

Our model showed differences in cigarette price elasticity figures of each income threshold (Table 2). When GNI per capita was lower than US\$5414 (Regime 1), cigarette price elasticity was the highest at -1.227 and income elasticity the lowest at 0.282 . When GNI per capita was between US\$5414 and US\$8385 (Regime 2), cigarette price elasticity reached -0.829 and income elasticity 0.423 . When GNI per capita was higher than US\$8385 (Regime 3), cigarette price elasticity was the lowest at -0.503 and income elasticity the highest at 0.576. In addition, among the $28 \mathrm{EU}$ countries cigarette prices in Eastern European countries ( $\left.\mathrm{Nei} P_{i t}^{*}\right)$ had a negative impact on cigarette consumption $(-0.057)$, indicating that lower cigarette prices in Eastern European countries led to higher domestic consumption.

Table 2 Threshold model estimates

\begin{tabular}{|c|c|c|}
\hline & \multicolumn{2}{|l|}{ Dependent variable: $\left(\operatorname{InC} C_{i t}^{*}\right)$} \\
\hline & Single-income threshold model & Double-income threshold model \\
\hline \multicolumn{3}{|l|}{ Independent variables } \\
\hline \multicolumn{3}{|l|}{$\ln P_{i t}^{*}$} \\
\hline Regime1(GNlit@US\$5418) & $-1.315^{b}(-0.737,-1.893)$ & $-1.227^{b}(-0.667,-1.787)$ \\
\hline Regime2(GNlit > US\$5418) & $-0.638^{\mathrm{b}}(-0.427,-0.849)$ & \\
\hline Regime2(US\$5418 < GNlit@US\$8385) & & $-0.829^{b}(-0.628,-1.030)$ \\
\hline Regime3(GNlit > US\$8385) & & $-0.503^{b}(-0.291,-0.715)$ \\
\hline \multicolumn{3}{|l|}{$\left.\ln G N\right|_{i t} ^{*}$} \\
\hline Regime1(GNlit@US\$5418) & $0.332^{b}(0.596,0.069)$ & $0.282^{b}(0.530,0.033)$ \\
\hline Regime2(GNlit > US\$5418) & $0.596^{b}(0.827,0.366)$ & \\
\hline Regime2(US\$5418 < GNlit@US\$8385) & & $0.423^{b}(0.685,0.261)$ \\
\hline Regime3(GNlit > US\$8385) & & $0.576^{\mathrm{b}}(0.787,0.336)$ \\
\hline$M P_{i t}^{*}$ & $-0.021^{\mathrm{b}}(-0.006,-0.035)$ & $-0.017^{\mathrm{b}}(-0.003,-0.032)$ \\
\hline Rural $_{\text {it }}^{*}$ & $1.637^{b}(3.006,0.269)$ & $1.616^{\mathrm{b}}(2.830,0.402)$ \\
\hline $\operatorname{lnNeiP} P_{i t}^{*}$ & $0.031(0.184,-0.122)$ & $-0.057(0.083,-0.197)$ \\
\hline Observations & 252 & 252 \\
\hline Number of country & 28 & 28 \\
\hline Sum of square error (SSE) & 0.355 & 0.311 \\
\hline Test for one threshold (income threshold) $\gamma 1$ & $43.66^{\mathrm{a}}(5418)$ & \\
\hline Test for two thresholds (income threshold) ${ }^{2}$ & & $36.61^{\mathrm{a}}(6494,32,040)$ \\
\hline
\end{tabular}

Regime 1 countries: Bulgaria, Romania

Regime 2 countries: Latvia, Poland

Regime 3 countries: Austria, Belgium, Croatia, Cyprus, Czech Republic, Denmark, Estonia, Finland, France, Germany, Greece, Hungary, Ireland, Italy, Lithuania, Luxembourg, Malta, Netherlands, Portugal, Slovakia, Slovenia, Spain, Sweden, United Kingdom

$P^{*}$ legal cigarette price, $G N I^{*}$ per capita national income, Rural rural population $\%, M P^{*}$ the number of MPOWER measures at the highest level of achievement Confidence intervals are shown in parentheses

${ }^{a}$ Statistically significant at $10 \%$ level

${ }^{\mathrm{b}}$ Statistically significant at $5 \%$ level 


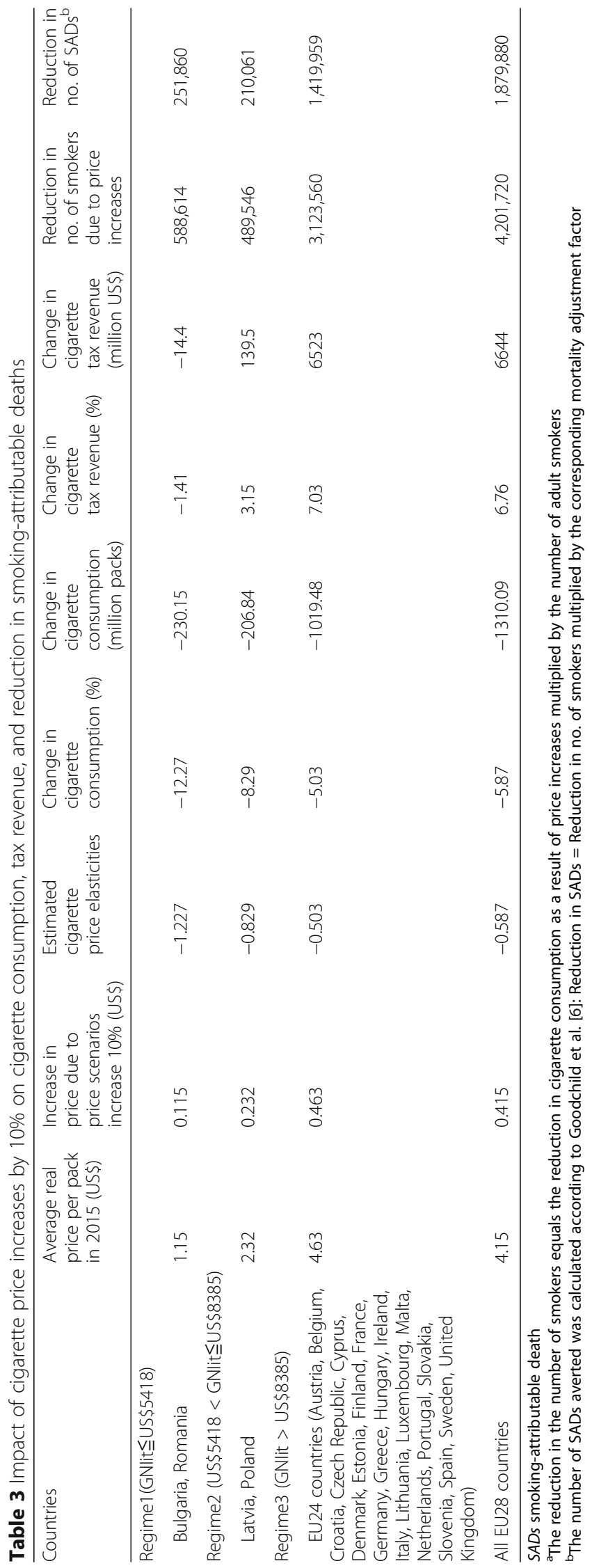


The number of MPOWER measures implemented at the highest level of achievement had a negative and statistically significant impact on cigarette consumption. Moreover, living in rural areas had a positive and statistically significant impact on cigarette consumption.

\section{Effect of cigarette prices on cigarette consumption, tobacco tax revenue, and smoking-related deaths}

Results of the administered price simulation showed that increases in cigarette prices (10\%) would reduce cigarette consumption the most in Bulgaria and Romania (per pack average price increase US $\$ 0.115$; consumption reduced: $12.27 \%$ ), followed by Latvia, and Poland (per pack average price increase US\$0.232; consumption reduced:8.29\%). The largest group of EU countries (in the following referred to as EU 24) had a smaller reduction in cigarette consumption (consumption reduced: 5.03\%) (Table 3).

Furthermore, the administered price simulation exhibited different effects on tax revenues among the three income groups. Bulgaria and Romania had a decrease in tax revenues $(-1.41 \%)$, whereas the EU24 countries had the highest average increase in tax revenues (7.03\%). Latvia and Poland, on the other hand, showed the lowest average increase in tax revenues (3.15\%) among all EU countries.

The simulated tax increase showed a significant impact on the number of averted smoking-attributable deaths (SADs) in all EU countries, but low-income countries were much more affected by the policy measure than the richer EU24 countries. According to the simulation, Bulgaria and Romania would avert over 251,860 deaths, followed by Latvia and Poland with 210,061 people, whereas the number of averted SADs would reach about 1.4 million in the EU24 zone.

\section{Discussion}

According to the results of this study, the price elasticity of cigarette demand in the 28 countries comprising the EU ranged from -0.503 to -1.227 . Countries with a GNI per capita lower than US\$5418 had the highest cigarette price elasticity $(-1.227)$. Countries with a GNI per capita higher than US $\$ 5418$ had lower cigarette price elasticities. These findings were similar to International Agency for Research on Cancer [28], who showed that low- and middle-income countries had a higher price elasticity. The results of this study thus further emphasise the importance of using economic measures as an intervention tool, especially in countries such as Bulgaria, and Romania, to reduce smoking.

In addition, this study estimated that income elasticities of cigarette demand ranged from 0.282 to 0.576 . Previously reported estimates ranged between 0.3 and 0.4 [4]. Despite differences in the size of the observed effect, elasticity figures suggest that income growth may have promoted cigarette consumption in the observed EU countries. That is, the effects of price increases on consumption might be offset by income growth in countries with a GNI per capita above US\$8385, where estimated cigarette price elasticity was lower than income elasticity. Thus, almost all EU countries would have to increase their cigarette prices substantially to reduce the increase in cigarette consumption that might be caused by income growth offset effects.

This study found that an average price increase of $10 \%$ throughout the EU would lead to an average increase in revenues by about $6.76 \%$, which is consistent with previously reported results [29]. Moreover, results of this study showed that the average tobacco taxation benefit of all EU countries significantly increased by 6644 million US\$ as a result of rising cigarette prices. In the future, increased cigarette prices in all EU countries are likely to reduce further the demand for cigarettes, and the appreciable increase in tobacco taxation revenues could be spent on the prevention and control of cigaretterelated diseases.

Additionally, this study revealed a negative relationship between the number of MPOWER measures at the highest level of achievement and cigarette consumption, which implies that $t$ the implementation of MPOWER measures can reduce cigarette consumption in the 28 EU countries. In most countries, however, the number of MPOWER measures at the highest level of achievement was below 2, That is, the number of implemented MPOWER tobacco control policies among EU countries was rather small. Therefore, efforts have to be made to implement far more MPOWER tobacco control policies as to achieve greater effects in reducing cigarette consumption as a whole.

This study showed that price increases in Bulgaria, and Romania had the greatest effects on reducing cigarette consumption among all EU countries, while experiencing a comparatively high prevalence of smoking [30]. In spite of gradual increases in tobacco taxes as to control tobacco consumption in recent years, cigarette prices in Bulgaria, and Romania have still remained comparatively low $[2,31]$. If these two countries continued to increase cigarette prices and the number of MPOWER tobacco control policies, current achievements could be significantly enhanced and funding for prevention and control programmes substantially be improved by larger taxation revenues. Transnational information was analysed in this study. However, the integrated analysis of transnational information may lead to incorrect inferences because different countries have different cigarette consumption structures. We thus suggest that all countries establish a cigarette consumption database and market-monitoring mechanism to undertake long-range tracking and analysis. 
Illicit trade of tobacco products has not been included in the study, as reliable data could not be obtained for all countries. Moreover, data on cigarette consumption analysed in this study refer to factory-made (FM) cigarettes.Roll-your-own (RYO) tobacco products have become popular in the EU in recent years and may influence consumption behaviour. Further research on price effects may thus address the issue of illicit trade and RYO cigarette use.

\section{Conclusion}

This study estimated that price elasticities of cigarette demand ranged from -0.503 to -1.227 . These figures were negative, indicating that cigarette consumption or demand in $28 \mathrm{EU}$ countries were inelastic during the study period. It is recommended that the $28 \mathrm{EU}$ countries should levy a higher tobacco tax to increase cigarette prices, thus reducing cigarette consumption. The subsequent increase in tobacco tax revenues would be instrumental in covering expenditures related to tobacco prevention and control programs.

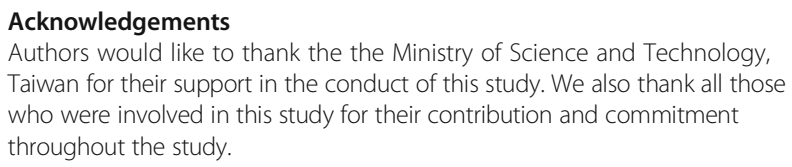

\section{Funding}

This study was funded by a grant through the the Ministry of Science and Technology (Grant number: NSC 103-2410-H-022-011-).

\section{Availability of data and materials}

Data supporting the results reported in the article can be obtained from the corresponding author.

\section{Authors' contributions}

CYY and JML performed the calculations and analyses reported in the text. $J M L$ and $L M H$ reviewed the literature for relevant data and documentation. JML and CYY drafted the manuscript which was edited and critically revised by $\mathrm{CYY}, \mathrm{CS}$ and $\mathrm{CJH}$. All authors read and approved the final manuscript.

\section{Ethics approval and consent to participate}

This article does not contain any studies with human participants performed by any of the authors. We received permission to use the data for this study from Euromonitor International.

\section{Consent for publication}

Not applicable.

\section{Competing interests}

The author(s) declare that they have no competing interests.

\section{Publisher's Note}

Springer Nature remains neutral with regard to jurisdictional claims in published maps and institutional affiliations.

\section{Author details}

'Department of International Trade, Overseas Chinese University, Taichung, Taiwan. ${ }^{2}$ Department of Shipping and Transportation Management, National Kaohsiung Marine University, 142, Hai-Chuan Rd. Nan-Tzu, Kaohsiung, Taiwan. ${ }^{3}$ Department of Marine Leisure Management, National Kaohsiung Marine University, Kaohsiung, Taiwan. ${ }^{4}$ Department of Finance, National Changhua University of Education, Changhua, Taiwan.
Received: 17 April 2017 Accepted: 17 August 2017

Published online: 21 September 2017

\section{References}

1. European Commission. Attitudes of Europeans towards tobacco and electronic cigarette. Eurobarometer: Special Report, 458, 2017. http://ec.europa.eu/ commfrontoffice/publicopinion/index.cfm/Survey/getSurveyDetail/ instruments/SPECIAL/surveyKy/2146. Accessed 24 July 2017.

2. James Reilly, Minister of Health intervention, ENVI public hearing on the Tobacco Products Directive, 25 February 2013.

3. Levy DL, Ellis JA, Mays D, Huang AT. Smoking-related deaths averted due to three years of policy progress. Bull World Health Organ. 2013;91(7):509-18.

4. Nguyen L, Rosenqvist G, Pekurinen M. Demand for tobacco in Europe. An econometric analysis of 11 countries for the PPACTE Project. National Institute for Health and Welfare: Helsinki; 2012.

5. Ahmad S, Franz GA. Raising taxes to reduce smoking prevalence in the US:A simulation of the anticipated health and economic impacts. Public Health. 2008;122(1):3-10.

6. Goodchild M, Perucic AM, Nargis N. Modelling the impact of increasing tobacco taxes on public health and finance. Bull World Health Organ. 2016; 94:250-257.

7. World Health Organisation. WHO technical manual on tobacco tax administration, 2010. http://www.who.int/tobacco/publications/tax_ administration/en/. Accessed 2 Feb 2017.

8. Chapman S, Richardson J. Tobacco excise and declining tobacco consumption: the case of Papua New Guinea. Am J Public Health. 1990; 80(5):537-40.

9. Hu TW, Mao Z. Effects of cigarette tax on cigarette consumption and the Chinese economy. Tob Control. 2002;11(2):105-8.

10. Gallet CA, List JA. Cigarette demand: a meta-analysis of elasticities. Health Econ. 2003;12(10):821-35.

11. Shohaimi S, Luben R, Wareham N, Day N, Bingham S, Welch A, Oakes S, Khaw KT. Residential area deprivation predicts smoking habit independently of individual educational level and occupational social class. A cross sectional study in the Norfolk cohort of the European Investigation into Cancer (EPIC-Norfolk). J Epidemiol Community Health. 2003;57(4):270-6.

12. Ross CE. Walking, exercising, and smoking: does neighborhood matter? Soc Sci Med. 2000;51(2):265-74

13. Idris Bl, Giskes K, Borrell C, Benach J, Costa G, Federico B, Helakorpi S, Helmert U, Lahelma E, Moussa KM, Ostergren PO, Prättälä R, Rasmussen NK, Mackenbach JP, Kunst AE. Higher smoking prevalence in urban compared to non-urban areas: time trends in six European countries. Health Place. 2007;13(3):702-12

14. Townsend JL, Roderick P, Cooper J. Cigarette smoking by socioeconomic group, sex, and age: effects of price, income, and health publicity. BMJ. 1994;309(6959):923-7.

15. Centers for Disease Control and Prevention (CDC). Response to increases in cigarette prices by race/ethnicity, income, and age groups-United States, 1976-1993. MMWR Morb Mortal Wkly Rep. 1998;47(29):605-9.

16. Beyond Smoking Kills. Protecting Children, Reducing Inequalities. London: $\mathrm{ASH}, 2008$.

17. World Health Organization. WHO Report on the Global Tobacco Epidemic, 2009-2015. Geneva; WHO, 2009-2016.

18. Johnston N, Kegö W, Wenngren C. Cigarette smuggling: Poland to Sweden. Institute for Security and Development Policy: Stockholm; 2016.

19. Chen SH, Lee JM, Liu HH, Wang HC, Ye CY. The cross-effects of cigarette and betel nut consumption in Taiwan: have tax increases made a difference? Health Policy Plan. 2011;26(3):266-73.

20. Huang BN, Yang CW. Demand for cigarettes revisited: an application of the threshold regression model. Agric Econ. 2006;34(1):81-6.

21. Euromonitor International (database online). Tobacco: global. Passport database. Euromonitor. London: Euromonitor; 2014. http://www. euromonitor.com/tobacco

22. World Bank. World Development Indicators (WDI). Washington, DC: World Bank; 2014

23. United Nations. World urbanization prospects: the 2014 revision. New York: United Nations Population Division; 2014.

24. Hansen BE. Threshold effects in non-dynamic panels: Estimation, testing, and inference. J Econom. 1999;93(2):345-68.

25. White $\mathrm{H}$. A heteroscedasticity-consistent covariance matrix estimator and a direct test for heteroscedasticity. Econom. 1980;48(4):817-38. 
26. Ranson K, Jha P, Chaloupka FJ, Nguyen SN. The effectiveness and costeffectiveness of price and other tobacco control policies. In: Jha P, Chaloupka FJ, editors. Tobacco control in developing countries. Oxford: Oxford University Press; 2000. p. 427-47.

27. Goodchild M, Perucic AM, Nargis N. Modelling the impact of raising tobacco taxes on public health and finance. Bull World Health Organ. 2016; 94(4):250-7.

28. International Agency for Research on Cancer. Effectiveness of tax and price policies for tobacco control. IARC handbooks of cancer prevention: tobacco control. Volume 14. Lyon: International Agency for Research on Cancer; 2011.

29. Waters H, Sáenz de Miera B, Ross H, Reynales Shigematsu LM. The economics of tobacco and tobacco taxation in Mexico. Paris: International Union Against Tuberculosis and Lung Disease; 2010

30. European Commission. Survey on tobacco - analytical report. Flash Eurobarometer No 253, 2009. http://ec.europa.eu/public_opinion/flash/fl_ 253_en.pdf. (Accessed 2 Feb 2017).

31. Jassem J, Przewoźniak K, Zatoński W. Tobacco control in Poland—successes and challenges. Transl Lung Cancer Res. 2014;3(5):280-5.

Submit your next manuscript to BioMed Central and we will help you at every step:

- We accept pre-submission inquiries

- Our selector tool helps you to find the most relevant journal

- We provide round the clock customer support

- Convenient online submission

- Thorough peer review

- Inclusion in PubMed and all major indexing services

- Maximum visibility for your research

Submit your manuscript at www.biomedcentral.com/submit
Biomed Central 